\title{
Oncological outcomes in the management of cT1-T2 cN0 penile squamous cell carcinoma
}

Juan Garisto; Madhur Nayan; Kamel Fadaak; Kathy Li; Advait Pandya; Ricardo Leao;

Peter Chung; Srikala S. Shridar; Joelle Helou; Girish S. Kulkarni

University of Toronto, Toronto, ON, Canada

Cite as: Garisto J, Nayan M, Fadaak K, et al. Oncological outcomes in the management of cT1-T2 cN0 penile squamous cell carcinoma. Can Urol Assoc J 2020 November 17; Epub ahead of print. http://dx.doi.org/10.5489/cuaj.6762

Published online November 17, 2020

$* * *$

\section{Abstract}

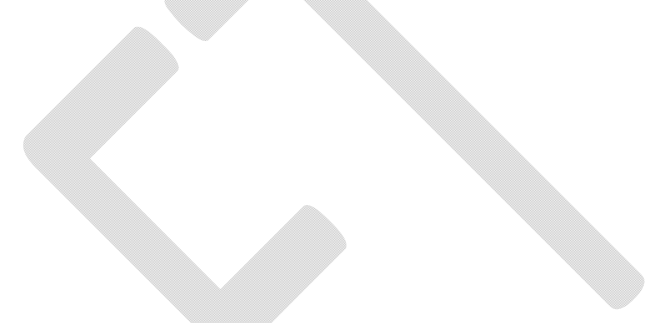

Introduction: Squamous cell carcinoma (SCC) of the penis is a rare disease comprising $1 \%$ of all male cancer. Options for the management of $\mathrm{cT} 1-\mathrm{T} 2 \mathrm{cN} 0$ penile SCC include partial penectomy (PP), considered the standard, and brachytherapy (BT), which offers acceptable local disease control and organ preservation. The purpose of our study was to assess and describe the oncological outcome for both treatments in a tertiary care center. Methods: We performed a contemporary retrospective study of patients with early-stage penile cancer treated surgically or by BT at a tertiary center between 2000 and 2016. Demographic, management, and followup data were obtained from an institutional database. Descriptive statistics and survival analysis using Kaplan-Meier plots were calculated. Local and regional recurrences were compared in both groups (BT vs. PP). Results: A total of 51 patients with cT1-T2N0 penile SCC treated with BT (35) and PP (16) were analyzed. Median followup was 37.1 (13.9-68) and 25.4 months (18-52.3) for the BT and PP group, respectively. Recurrence developed in seven (20\%) patients treated with BT. Median time to recurrence was 35.2 months (range 2.9-95.8). No recurrences were reported in patients treated with PP. Forty-four $(86.2 \%)$ patients were alive with no evidence of disease at the last followup. Overall survival was $62.7 \%$. Complications after primary tumor treatment were urethral stenosis $(15.7 \%)$, penile necrosis $(7.8 \%)$, and local infection $(2 \%)$.

Conclusions: PP provides acceptable local control with organ preservation in early-stage penile SCC. BT was able to offer organ preservation in $69 \%$ of men. Future prospective studies are needed to compare other organ-conserving treatment modalities with PP. 


\section{Introduction}

Carcinoma of the penis is rare, with an estimated incidence of approximately 1 per 100,000 men in North America and Western European countries ${ }^{1}$. Likewise in Canada, Cancer Statistics from 2016 reported about 160 new cases yearly and 60 penile cancerrelated deaths ${ }^{2}$.

Historically, the treatment goal for penile carcinoma $(\mathrm{PeCa})$ was a complete excision of the primary lesion with adequate margins. However, new trends towards organ-preserving techniques have emerged, seeking to diminish the psycho-oncological impact on patients' quality of life ${ }^{3}$. Various guidelines including the National Comprehensive Cancer Network and the Canadian Association of Genitourinary Medical Oncologists described different local treatments for cT1-2 cN0 penile squamous cell carcinoma (SCC) ${ }^{4-6}$. Management techniques range from organ-preserving surgeries (glansectomy, laser therapy, Mohs micrographic surgery) to more invasive methods such as partial (PP) ${ }^{7}$ or total penectomy, depending on the size of the lesion, pathological grade, and stage of the disease. Additional modalities, such as external beam radiation therapy $^{8}(\mathrm{RT})$ and/or interstitial brachytherapy $(\mathrm{BT})^{9}$, have also been reported as alternative organ-preserving approaches with good results in selected patients with cT1-2 lesions $<4 \mathrm{~cm}$ in diameter.

Penile BT has historically achieved satisfactory local control with estimated 10year penile preservation rates of $67 \%$ to $72 \%{ }^{8}$. Both approaches (PP or penile BT) can provide acceptable local control with the advantage of organ preservation in early stage disease. Given the low incidence of this disease, management is often guided by local experience. A recent single-institution series from the University of Western Ontario examined the treatment regimens of men with penile SCC demonstrating the limited incidence of this disease within Canada and making evident the paucity of institutional data from tertiary centers ${ }^{10}$. The lack of information in PeCa necessitates the examination of outcomes from experienced centers that takes advantage of a multidisciplinary approach to this disease. The objective of this study was to describe the oncological outcomes of PP versus BT for cT1-T2 $\mathrm{cN} 0$ penile cancer.

\section{Methods}

\section{Study population}

Upon obtaining institutional research board approval, we performed a retrospective study of men diagnosed with penile SCC at the University Health Network - Princess Margaret Cancer Centre (UHN-PM) between 2000 and 2016. From our institutional database, we identified patients with early stage (cT1-2cN0) disease treated with penile BT and/or PP and obtained information on demographics, histopathological data, oncological 
outcomes, and complications after primary intervention. Patients with carcinoma in situ (CIS), non-SCC histology or primary urethral carcinoma were excluded from this analysis. Local recurrence was defined as disease relapse 3 months or longer after primary treatment. Categories for recurrence were established as local (in the penile remnant), regional (groin/pelvic nodes) or distant (metastasis). Mortality data were obtained using the UHN-PM Cancer Registry.

\section{Primary tumor treatment}

At the UHN-PM, all men had a biopsy proven penile SCC as part of the initial histological diagnosis to identify adverse pathological features. Thereafter, based on an integrated multidisciplinary approach, patients were selected for initial management based on clinical and radiological staging and patient parameters. Physical examination and imaging studies (computerized tomography of the chest, abdomen and pelvis or penile magnetic resonance) were part of pre-treatment staging. Once stage cT1 and cT2 cN0M0 tumors were confirmed, PP or BT was offered to patients with invasive tumors of the mid to distal penis. Final treatment was selected by patient and physician choice. PP involved a surgical resection for invasive tumors with a distance of $2 \mathrm{~cm}$ from the surgical margin of resection. Penile BT was performed under general anesthesia. Implant principles and dose prescription were based on the Paris system of dosimetry ${ }^{11}$. In men with an intact prepuce, circumcision prior to BT was performed to allow full exposure of the tumor, eliminate risk of significant fibrosis of the prepuce and facilitate clinical examination in the follow up period. In addition to the treatment of the primary lesion, patients with non-palpable inguinal lymph nodes were stratified according to the European Association of Urology guidelines into low, intermediate, and high-risk groups base on the histology of the primary lesion ${ }^{6,12}$. Men with intermediate or high-risk disease were offered modified inguinal lymph node dissection (boundaries included the apex of the femoral triangle distally, the sartorius muscle laterally, the adductor longus muscle medially, the inguinal ligament superiorly and the fascia lata).

Pelvic lymph node dissection was performed if the patient had $\geq 2$ positive nodes at inguinal lymph node dissection or extranodal extension. Dedicated uropathologists reviewed all excised specimens. Tumors were staged according to the 2010 AJCC $7^{\text {th }}$ edition $^{13}$.

After the primary treatment, patients were followed at the UHN-PM clinic every 3 months for the first 2 years and 6 months thereafter for a minimum of 5 years ${ }^{6}$. Examination for regional recurrence including clinical assessment of urinary symptoms and inguinal lymphadenopathy was performed at each visit with appropriate image studies. 


\section{Statistical analysis}

Descriptive statistics were used to summarize the data, with means and interquartile ranges used for continuous variables and frequency tables for categorical variables. We used the Kaplan-Meier method to evaluate overall survival (time from diagnosis to death from any cause, in months), cancer specific survival (time from diagnosis to death from cancer, in months). Statistical analysis was performed using Prism 5.0a (Graphpad, San Diego, US).

\section{Results}

\section{Demographics}

A total of 53 consecutive patients with cT1-2cN0 SCC of the penis treated at the UHNPM met inclusion criteria. Two patients were excluded due to lack of follow-up data, resulting in a final cohort of 51 patients for analysis. Both groups of patients were similar in age, Charlson Comorbidity Index, tumor size, and tumor location (Table 1). Disease stage and grade influenced the local treatment approach; PP was preferred for T2 tumors (37.5\% vs $14.3 \%$ for brachytherapy), while patients with low-grade disease were preferentially treated primarily with penile brachytherapy.

\section{Outcomes and survival analysis}

Table 2 outlines the median follow-up for both groups of patients. Forty-four patients were alive with no evidence of disease at the last follow-up. When comparing both approaches for T1-2cN0 penile cancer disease, we found differing clinical outcomes. Overall, 7 (20\%) men treated primarily with BT had local/regional recurrence (Table 3). Three were further treated with salvage PP and lymph node dissection while the other two patients had salvage amputation only. From those patients, 4 and 3 had histologically confirmed local and regional recurrence for penile SCC, respectively. Median time to recurrence was 35.2 months (range 2.9-95.8). The overall survival for cT1-T2 cNx penile cancer was $62.7 \%$ (Figure 1a). There were no recurrences in the 16 men initially managed with PP. CSS was $88 \%$ and $100 \%$ for BT and PP group at 120 months, respectively (Figure 1b).

In the BT cohort, 4 patients died from the disease. One of the four patients had an initial local recurrence and the remaining three had regional recurrence. Six patients died from other causes.

\section{Complications}

The most common complication after primary tumor treatment was urethral stenosis, occurring in 8 cases (15.7\%). Seven cases occurred after brachytherapy and one was found after PP. All were managed with meatal dilatation. In the BT group, 4 patients 
developed necrosis of the glans/corporeal tip and were treated with partial penectomy. Local infection developed in 1 case after brachytherapy and was treated with topic antibiotics. No systemic complications were seen.

\section{Discussion}

Various treatment modalities have been used in the management of cT1-T2 cN0 penile SCC. As there are no randomized trials to compare the results of different treatment modalities, retrospective studies are performed yet are limited due to the small number of patients and the multiple treatment options that have been used. In our study, we investigated the oncological outcomes between conventional surgical treatment (partial penectomy) and a conservative approach (penile brachytherapy) for early stage penile carcinoma. Compared with BT, PP yielded superior local oncologic outcomes. However, BT did afford $69 \%$ of men an opportunity for organ preservation.

In $\mathrm{PeCa}$, primary treatment failure may translate into a reduction in diseasespecific survival ${ }^{14}$. In our series, PP for SCC of the penis provided excellent oncologic outcomes comparable to previously published reports. According to the published literature, the recurrence rate after penile amputation has been reported to be between 5 and $10 \%$. Rampelakos et al. ${ }^{15}$ reported a series of 360 cases of SCC treated with PP. From those, 227 were partial amputations with no local recurrence during the 10-year follow-up. Furthermore, Ornellas et al. ${ }^{16}$ published a series of 522 patients with primary PP for penile cancer reporting 25 (4\%) with local recurrence with a follow-up of 11 months. In our series, none of the 16 patients that underwent PP had local or regional recurrence whereas a proportion of the BT patients required salvage PP and nodal dissection.

The main advantage of radiotherapy is organ preservation. In our series, $35 \mathrm{BT}$ patients, $20 \%$ had loco-regional recurrence. In the series of Crook et al. ${ }^{17}$, of the 49 patients who received penile BT, $3(6 \%)$ had local recurrence for early stage penile cancer at a median follow-up of 33.4 months. Rozan ${ }^{8}$ et al. presented the largest series of 259 patients treated by BT (184 patients) alone or surgery with BT (75 patients), with local control rates of $88 \%$ at 3 years in both groups and penis conservation in $84 \%$ of patients. Escande et al. ${ }^{18}$ described a series of 201 patients treated with BT reporting local relapses in 37 patients with a median follow-up of 10.7 years and local control rate of $82 \%$. Our institutional experience is consistent with other reports of penile BT.

The most common complications reported in our series were meatal stenosis and penile necrosis, seen in $7(20 \%)$ and $4(11.4 \%)$ patients treated with BT, respectively. In a retrospective review of a cohort of 113 patients with invasive SCC of the penis, de Crevoisier et $\mathrm{al}^{19}$ found urethral stenosis requiring at least one meatal dilatation in 26 patients with a 10 -year stenosis rate of $29 \%$. Penile necrosis was less frequent, but does 
have a significant impact on quality of life. Different series reported that $9 \%$ to $43 \%$ of these complications require salvage $\mathrm{PP}^{9,17,20-22}$. These complications may be related to dose/volume relationships.

The presence and the extent of inguinal lymph node (LN) metastasis have been shown to be the most important factors for the prognosis of patients with penile cancer ${ }^{23}$. In our experience, the percentage of $\mathrm{LN}$ recurrences was $5.8 \%$ in the setting of clinically negative groins at diagnosis. There may have been some difference between BT and PP patients in risk of nodal disease however 2 of the BT patients had a late recurrence $(>3$ years) meaning that extended follow-up is recommended for these patients due to the probability of remote failure several years after initial treatment.

Our study has several limitations. This is a retrospective, descriptive, singleinstitution cohort of a small number of patients with limited follow-up and it is therefore subject to inherent biases. In this regard, other toxicities such as telangiectasia, fibrosis and pain may have been underestimated. Furthermore, the small number of events ( 7 patients with local recurrence) precluded a multivariate analysis. We also recognize that our investigation lacks data on sexual function and quality of life (QOL) after penis BT compared to amputation. Finally, management of the disease was performed over a long time frame during which the understanding of $\mathrm{PeCa}$ has evolved, thus potentially affecting treatment and case selection.

Future research should assess the functional, cosmetic and oncological differences between treatments options for early stage PeCa including penis conserving strategies (local excision, laser treatment), partial amputation and radiotherapy. This may require centralization of $\mathrm{PeCa}$ management or multi-institutional collaborations to make meaningful comparisons ${ }^{24,25}$.

\section{Conclusions}

In patients with T1-2cN0 SCC of the penis, PP provided acceptable local control. While BT offers organ preservation with a presumed advantage in QOL, salvage surgery for local recurrence remains an important component in management of this disease. Further multi-institutional prospective studies comparing PP and BT are necessary to determine differences in local recurrence, toxicity, and quality of life. 


\section{References}

1. Backes DM, Kurman RJ, Pimenta JM, et al. Systemic review of human papillomavirus prevalence in invasive penile cancer. Cancer Causes Control 2009 May; 20(4): 449-57.

2. Canadian cancer Society's Steering Committee on Cancer Statistics. Canadian Cancer Statistics 2016. Toronto, ON: Canadian Cancer Society 2016.

3. Kieffer JM, Djajadiningrat RS, van Muilekom EA. Et al. Quality of life for patients treated for penile cancer. J Urol. 2014 Oct;192(4):1105-10.

4. National Comprehensive Cancer Network. Penile Cancer (Version 1.2015). NCCN Clinical Practice Guidelines in Oncology; 2014.

5. Hakenberg OW, Comperat E, Minhas S, et al. EAU guidelines on penile cancer. 2014 update. Eur Urol 2015; 67:142-50.

6. Richter S, Ruether JD, Wood L, et al. Management of carcinoma of the penis: Consensus statement from the Canadian Association of Genitourinary Medical Oncologist (CAGMO). Can Urol Assoc J. 2013 Nov-Dec;7(11-12):E797-811.

7. Loughlin KR. Surgical management of penile carcinoma: The primary lesion. $\mathrm{Br}$ J Urol Int 2006; 97:665-667.

8. Gerbaulet A, Lambpin P. Radiation therapy of cancer of the penis: Indications, advantages and pitfalls. Urol clin North Am. 1992; 19:325-332.

9. Rozan R, Albuisson E, Giraud B, et al. Interstitial brachytherapy for penile carcinoma: A multicentric survey. Radiother Oncol 1995; 36:83-93.

10. Beech B, Izawa J, Pautler S, et al. Penile cancer: Perspective from a Canadian tertiary care centre. Can Urol Assoc J. 2015 Sep-Oct; 9(9-10):315-9.

11. Pierquin B, Chassagne D, Wilson F. Modern Brachytherapy. New York: Massom Pub; 1987.

12. Hakenberg OW, Comperat EM, Minhas S, et al. EAU guidelines on penile cancer: 2014 update. Eur Urol. 2015 Jan;67(1):142-50.

13. Clark PE, Spiess PE, Agarwal N, et al. Penile cancer: Clinical Practice Guidelines in Oncology. J Natl Compr Canc Netw. 2013 May 1;11(5):594-615.

14. Lont AP, Galle MP, Meinhardt W, et al. Penis conserving treatment for T1 and T2 penile carcinoma: clinical implications of local recurrence. J Urol 2006;176:575-80.

15. Remplelakos A, Bastas E, Lymperakis $\mathrm{CH}$, et al. Carcinoma of the penis: experience from 360 cases. J BUON. 2004 Jan-Mar;9(1):51-5.

16. Ornellas AA, Kinchin EW, Nobrega BL et al. Surgical treatment of invasive squamous cell carcinoma of the penis: Brazilian National Cancer Institute longterm experience. J Surg Oncol. 2008 May 1;97(6): 487-95.

17. Crook JM, Jezioranski J, Grimard L. et al. Penile brachytherapy: results for 49 patients. Int J Radiat Oncol Biol Phys. 2005 Jun 1;62(2):460-7.

18. Escande A, Haie-Meder C, Mazeron R. et al. Brachytherapy for Conservative treatment of invasive penile carcinoma: prognostic factors and long-termin analysis of outcome. Int J Radiat Oncol Biol Phys. 2017 Feb(17)304373-X. 
19. De Crevoisier R, Slimani K, Sanfilippo N. et al. Long-Term results of brachytherapy for carcinoma of ht penis confined to the Glans (N- or NX). Int J Radiat Oncol Biol Phys. 2009 Jul 15;74(4):1150-6.

20. Pimenta A, Gutierrez C, Mosquera D. et al. Penile brachytherapy-retrospective review of a single institution. Brachytherapy. 2015;14:525-30.

21. Crook J, Ma C, Grimard L. Radiation therapy in the management of the primary penile tumor: an update. World J Urol. 2009;27:189-196.

22. Delaunay B, Soh PN, Delannes M, et al. Brachytherapy for penile cancer: efficacy and impact on sexual function. Brachytherapy. 2014;13:380-387

23. Protzel C, Alcaraz A, Horenblas S. et al. Lymphadenectomy in the surgical Management of Penile Cancer. Eur Urol. 2009 May;55(5):1075-88.

24. Matulewicz RS, Flum AS, Helenowski I, et al. Centralization of Penile Cancer Management in the United States: A Combined Analysis of the American Board of Urology and National Cancer Data Base. Urology 2016 Apr;90:82-8.

25. Patel MI, Yuminaga Y, Bang A. et al. Volumen-outcomes relationship in penile cancer treatment: a population based patterns of care and outcomes study from Australia. BJU Int. 2016 Oct;118 Suppl 3:35-42.

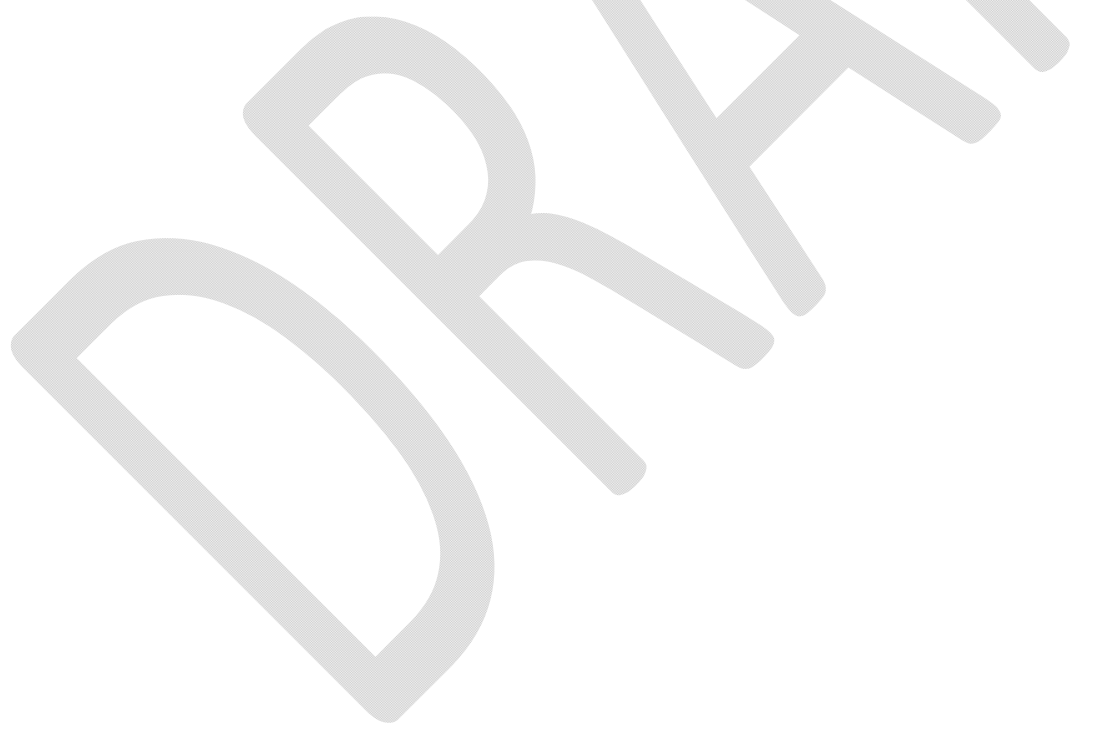




\section{Figures and Tables}

Fig. 1. (A) Cumulative proportion (Kaplan-Meier curves) of overall survival after stratification by type of treatment (brachytherapy vs surgery). (B) Cumulative proportion (Kaplan-Meier curves) of cancer-specific survival (CSS) after stratification by type of treatment (brachytherapy vs surgery).

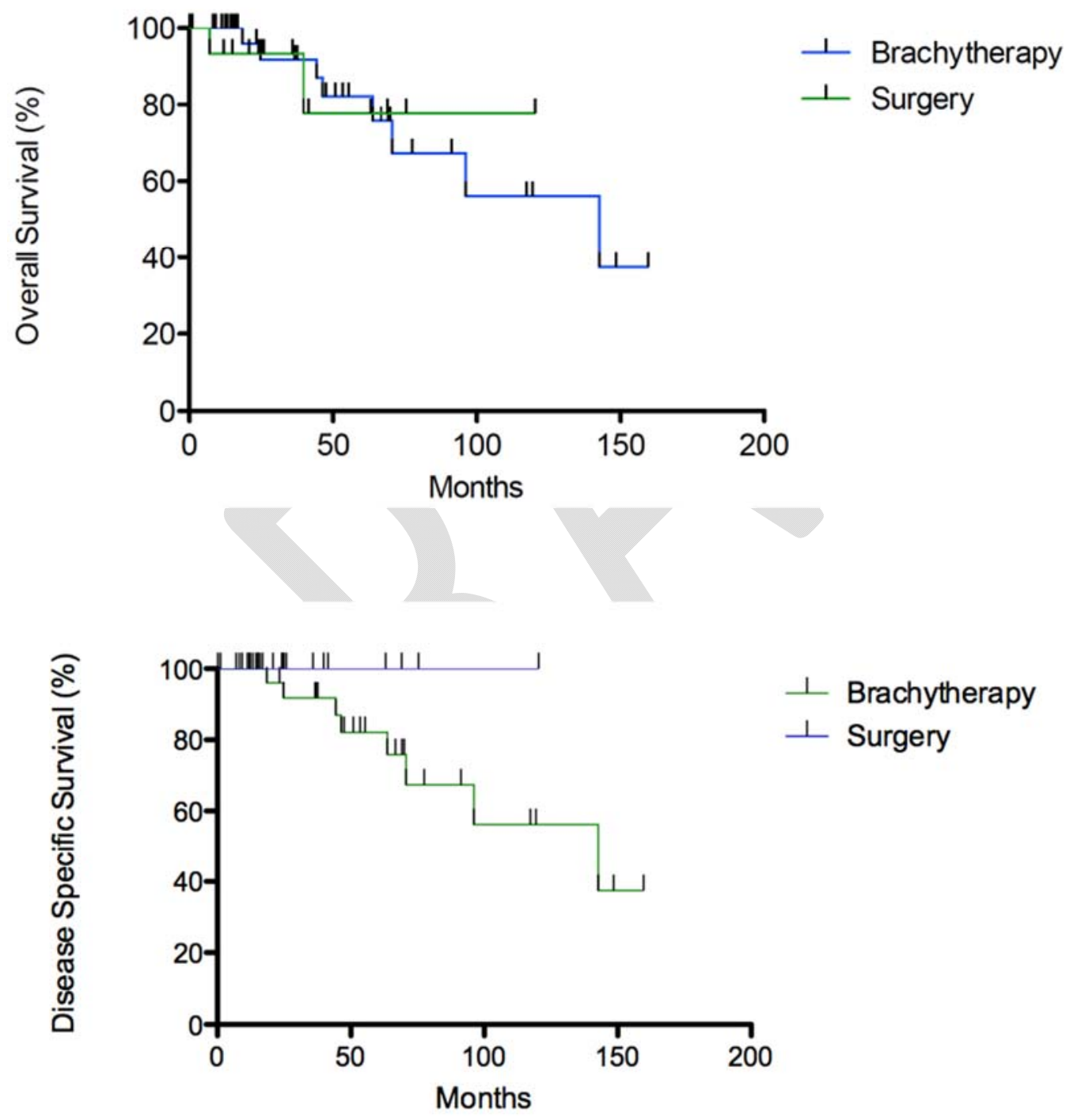




\begin{tabular}{|c|c|c|}
\hline \multirow[t]{2}{*}{ Variables } & \multicolumn{2}{|c|}{ Treatment modalities } \\
\hline & Brachytherapy $(n=35)$ & Partial penectomy $(n=16)$ \\
\hline $\begin{array}{l}\text { Age (years) at diagnosis, median } \\
\text { (IQR) }\end{array}$ & $63(50-72)$ & $66(50-90)$ \\
\hline Charlson index, median (IQR) & $2(2-2)$ & $2(2-2)$ \\
\hline Tumor size $(\mathrm{cm})$, median (IQR) & $2.0(1.5-2.5)$ & $3.0(2.4-3.0)$ \\
\hline \multicolumn{3}{|l|}{ Tumor location, $\mathrm{n}(\%)$} \\
\hline Glans & $29(82.9)$ & $15(93.8)$ \\
\hline Shaft & $1(2.9)$ & $1(6.2)$ \\
\hline Foreskin & $5(14.3)$ & $0(0)$ \\
\hline Clinical T stage (n (\%)) & $x^{2}$ & \\
\hline T1N0M0 & $30(85.7)$ & $10(62.5)$ \\
\hline T2N0M0 & $5(14.3)$ & $6(37.5)$ \\
\hline \multicolumn{3}{|l|}{ Pathological T stage, $\mathrm{n}(\%)$} \\
\hline $\mathrm{T} 1$ & - & $8(50)$ \\
\hline $\mathrm{T} 2$ & - & $8(50)$ \\
\hline \multicolumn{3}{|l|}{ Pathological N stage, n (\%) } \\
\hline $\mathrm{Nx}$ & $21(60.0)$ & $5(31.2)$ \\
\hline N0 & $14(40.0)$ & $11(68.8)$ \\
\hline \multicolumn{3}{|l|}{ Grade, $\mathrm{n}(\%)$} \\
\hline G1 & $16(45.7)$ & $4(25.0)$ \\
\hline+2 & $19(54.3)$ & $10(62.5)$ \\
\hline+2 & $0(0)$ & $2(12.5)$ \\
\hline
\end{tabular}

IQR: interquartile range; SCC: squamous cell carcinoma. 


\begin{tabular}{|l|c|c|}
\hline \multicolumn{3}{|l|}{ Table 2. Partial penectomy vs. brachytherapy in patients with cT1-2, N0 disease } \\
\hline Survival outcomes & Brachytherapy $(\mathbf{n = 3 5})$ & Partial penectomy (n=16) \\
\hline $\begin{array}{l}\text { Followup (months), median } \\
(\text { IQR) }\end{array}$ & $37.1(13.9-68.0)$ & $25.4(18.0-52.3)$ \\
\hline Recurrence, n (\%) & $7(20.0)$ & $0(0)$ \\
\hline Cancer-specific death, n (\%) & $4(11.4)$ & $0(0)$ \\
\hline $\begin{array}{l}\text { Death due to any cause, } \mathrm{n} \\
(\%)\end{array}$ & $6(17.1)$ & $2(12.5)$ \\
\hline
\end{tabular}

IQR: interquartile range. 


\begin{tabular}{|c|c|c|c|c|c|c|c|c|c|}
\hline Patient & $\begin{array}{l}\text { Initial treatment } \\
\text { for recurrence }\end{array}$ & $\mathbf{p T}$ & Grade & LVI+ & $\begin{array}{l}\text { Months } \\
\text { RFS }\end{array}$ & $\begin{array}{l}\text { Recurrence } \\
\text { location }\end{array}$ & $\begin{array}{l}\text { Months } \\
\text { survival }\end{array}$ & Comments & Status \\
\hline 1 & $\begin{array}{c}\mathrm{PP}+\text { bilateral groin } \\
\text { LND }\end{array}$ & pT3N0 & 2 & Yes & 95 & Penis & 138 & $\begin{array}{c}\text { Progression after total } \\
\text { penectomy; metastases to } \\
\text { lungs }\end{array}$ & Death \\
\hline 2 & PP & $\mathrm{pT} 2$ & 1 & No & 73 & Penis & 160 & - & Alive \\
\hline 3 & $\begin{array}{l}\text { Bilateral } \\
\text { LND }\end{array}$ & pTxN1 & - & - & 14 & Groin & 95 & $\begin{array}{c}\text { Progression to lungs } \\
\text { metastasis. Death related } \\
\text { with PC }\end{array}$ & Death \\
\hline 4 & $\mathrm{PP}+$ bilateral LND & pT1N1 & 2 & Yes & 7 & Penis/Groin & 18 & - & Death \\
\hline 5 & $\begin{array}{c}\text { Bilateral/pelvic } \\
\text { LND }\end{array}$ & pTxN2 & - & & 62 & Groin/pelvis & 64 & - & Death \\
\hline 6 & $\mathrm{PP}+$ bilateral LND & pT2N0 & 1 & No & 3 & Penis & 104 & - & Alive \\
\hline 7 & $\mathrm{PP}$ & pT1 & 1 & No & 35 & Penis & 48 & - & Alive \\
\hline
\end{tabular}

BT: brachytherapy; LND: lymph node dissection; LVI: lymphovascular invasion; PP: partial penectomy; PC: penile cancer; RFS: relapse-free survival. 